\title{
Incidence, severity and factors related to drug-induced keratoepitheliopathy with glaucoma medications
}

This article was published in the following Dove Press journal:

Clinical Ophthalmology

14 April 2010

Number of times this article has been viewed

\author{
Takeo Fukuchi \\ Kimiko Wakai \\ Kieko Suda \\ Tomoko Nakatsue \\ Hideko Sawada \\ Hiroaki Hara \\ Jun Ueda \\ Takayuki Tanaka \\ Akiko Yamada \\ Haruki Abe \\ Division of Ophthalmology and \\ Visual Science, Graduate School of \\ Medical and Dental Sciences, Niigata \\ University, Niigata, Japan
}

Purpose: To evaluate the incidence, severity, and factors related to drug-induced keratoepitheliopathy in eyes using antiglaucoma eye drops.

Patients and methods: In a cross-sectional study, 749 eyes from 427 patients who had used one or more antiglaucoma eye drops were examined at Niigata University Medical and Dental Hospital or related facilities. The incidence and severity of superficial punctate keratitis (SPK), patient gender and age, type of glaucoma, and type of eye drops were recorded. SPK was graded according to the AD (A, area; D, density) classification. The severity score (SS) was calculated from $\mathrm{A} \times \mathrm{D}$.

Results: SPK was observed in $382(51.0 \%)$ of 749 eyes that had received any type of antiglaucoma eye drops. While 254 eyes (33.9\%) were classified as A1D1 (SS 1), 34 eyes (4.6\%) had severe SPK with SS 4 or more. The number of eye drops and the total dosing frequency per day were significantly greater in SPK-positive eyes than in eyes without SPK. The number of eye drops was proportional to the frequency and severity of SPK. Among eyes that were treated with three or more eye drops, SPK was more severe and more frequent in older patients ( $\geq 71$ years). In addition, a considerable difference was detected for each type of glaucoma.

Conclusion: Drug-induced keratoepitheliopathy is often observed in eyes that have received recent antiglaucoma eye drops. The number of eye drops, the total dose frequency per day, patient age, and type of glaucoma may affect this condition. We have to consider not only the effects on intraocular pressure but also the incidence and severity of drug-induced keratoepitheliopathy as a frequent side effect of glaucoma medications.

Keywords: glaucoma, medications, eye drops, keratoepitheliopathy, AD classification

\section{Introduction}

Almost 10 years have passed since prostaglandin analogs $\mathrm{s}^{1-5}$ and topical carbonic anhydrase inhibitors ${ }^{6-8}$ became available as expanded glaucoma medical options, even in Japan. Later, $\alpha 1$ or $\alpha 1 \beta$ blockers were introduced as treatments with alternative hypotensive mechanisms. Timolol eye drops in gel-like formulations ${ }^{9}$ and long-acting carteolol were introduced as daily medications. Suspension-type eye drops ${ }^{8}$ reduced irritation at the time of application. Furthermore, preservative- or benzalkonium chloride (BAC)-free eye drops have become available to reduce the influence of eye drops on the ocular surface. ${ }^{4,5,10-12}$ Because of these advances, we can now choose from many antiglaucomatous eye drops in various forms with different mechanisms, and determine the ones that are most suitable for each patient. It is important for glaucoma management to increase treatment efficacy and adherence. We compared the average follow-up intraocular pressure (IOP) from 10 years ago to those of recent
Division of Ophthalmology and Visua Science, Graduate School of Medical and Dental Sciences, Niigata University, I-757 Asahimachi-dori Niigata, Niigata 95I-85I0, Japan

Tel +81252272296

Fax +8I 252270785

Email tfuku@med.niigata-u.ac.jp 
years in patients with primary open-angle glaucoma (POAG) or normal tension glaucoma (NTG). The recent follow-up IOP was significantly lower than the IOP 10 years ago. This reduction was dependent on medical therapy and not surgical therapy. The medical therapy for IOP reduction, which is the primary goal of glaucoma treatment, has greatly improved over the last 10 years.

However, drug interactions and side effects have not been satisfactorily evaluated for many antiglaucoma eye drops. Topical medication is a very specific treatment in ophthalmological clinical practice. Eye drops have a number of influences that can harm the ocular surface. Because the volume of one drop is too much for the conjunctival sac, tear components including electrolytes, proteins, and mucin must be removed from the tear film. ${ }^{13}$ These drops can also alter ocular $\mathrm{pH}$ and osmotic pressure. Furthermore, eye drops are known to inhibit the proliferation, regeneration, and turnover of the corneal epithelium. ${ }^{13}$ Eye drops are composed of the active drug as well as preservatives and a buffer solution. BAC has been frequently used as a preservative in eye drops for many years. ${ }^{13-16} \mathrm{BAC}$ is easily solubilized in water and is easy to handle. Because BAC has strong antibacterial activity, these eye drops can be safe for a long time period. However, BAC is highly toxic to the normal corneal epithelium and is closely associated with drug-induced keratoepitheliopathy and allergic conjuncitivis or blepharitis. ${ }^{14-16}$ Drug-induced keratoepitheliopathy is probably the most frequent and unavoidable side effect of glaucoma medications. ${ }^{14-30}$ However, treatment for chronic glaucomas, including POAG and NTG, requires that eye drops are applied for a lifetime. In cases of secondary glaucoma, multiple eye drops are often used simultaneously. Many clinical ${ }^{18-23}$ and experimenta ${ }^{24-27}$ studies have examined drug-induced keratoepitheliopathy. In particular, a number of studies have examined the effects of timolol maleate, when used as the first choice for long-term glaucoma treatment. ${ }^{20-22}$ However, most previous reports evaluated drug-induced keratoepitheliopathy for each drug, and not the multiple drug combinations that are used in clinical practice. Only Inoue et $\mathrm{al}^{23}$ reported that multiple antiglaucoma eye drops, including a prostaglandin analog and a carbonic anhydrase inhibitor, were associated with keratoepitheliopathy and ocular factors.

Therefore, we examined the incidence, severity, and factors related to drug-induced keratoepitheliopathy in clinical practice. The primary aim of this study was to clarify the circumstances of drug-induced keratoepitheliopathy using a combination of more recent antiglaucoma eye drops.
In addition, we discuss how to reduce and determine the acceptable side effects for long-term glaucoma treatment.

\section{Patients and methods}

This study is a practise-based, cross-sectional, observational study. The patients included in this study had some type of glaucoma and were using one or more antiglaucoma eye drops. The patients were followed up at the Niigata University Medical and Dental Hospital or related facilities. Ten ophthalmologists randomly collected patients at each clinic for approximately four weeks starting in mid-April of 2008. The total number of cases included 749 eyes from 427 patients.

Keratoepitheliopathy was detected using a fluorescein-based staining method. Prior to any ophthalmological examination or treatment, including topical anesthesia, the patient's cornea was stained using fluorescein paper (Shouwa Yakuhin Co., Tokyo, Japan) and then examined after at least 10 seconds. Superficial punctate keratitis (SPK) was detected in each eye and the severity was determined by slit lamp examination. In this study, even very mild SPK was considered positive. Using a check list, we recorded patient gender, age, type of glaucoma, eye(s) affected, SPK and its severity, total number of eye drops, total dose frequency per day for glaucoma, and other disorders. Only preservative-free tear-like eye drops were excluded when counting the number of eye drops used per day and the dose frequency per day. SPK was classified according to the $\mathrm{AD}$ classification devised by Miyata et $\mathrm{a}^{31}$ The severity score (SS) was calculated as A $\times \mathrm{D}$.

Seven hundred forty-nine eyes from 427 cases (both eyes in 322 cases and one eye in 105 cases) were included in this study. The average age was $69.1 \pm 12.2$ years $( \pm$ standard deviation, 27-94 years). While 335 eyes in 198 cases were in male patients, 414 eyes in 229 cases were from females. POAG including NTG was diagnosed in 566 eyes, ocular hypertension in 14 eyes, primary angle closure or glaucoma in 40 eyes, pseudoexfoliation glaucoma (XFG) in 52 eyes, glaucoma with uveitis or iridocyclitis in 22 eyes, neovascular glaucoma (NVG) in 15 eyes, and other conditions in 40 eyes. Clinical diagnosis of each glaucoma type was basically according to guidelines from the European Glaucoma Society $^{32}$ and the Japan Glaucoma Society. ${ }^{33}$

\section{Statistical analysis}

For statistical analysis, a nonparametric Mann-Whitney $U$-test, was used for the average SS, number of eye drops, and total dose frequency per day, because these parameters do not follow a normal distribution. The incidence of SPK was analyzed by Chi-square test. 


\section{Results}

In our study patients, only SPK presented as drug-induced keratoepitheliopathy. SPK was detected in 382 (51.0\%) of 749 eyes. Both the average number of eye drops and the average total frequency of doses per day were significantly greater in eyes with SPK than those without SPK by Mann-Whitney $U$-test (Table 1).

The results are presented in Table 2 by the AD classification. While 254 eyes (33.9\% of the total and $66.5 \%$ of SPK-positive) were classified as A1D1 (SS 1), 34 eyes (4.6\%) had severe SPK with an SS of 4 or more. Figure 1 shows the severity scores by the number of eye drops. SPK was positive in 128 of 348 eyes (36.2\%) that used eye drops. SPK was positive in 167 of 284 eyes (58.8\%) with two, in 74 of 103 eyes (72.8\%) with three, and in all eyes (14 total, $100 \%$ ) with four or five eye drops. The frequency of eyes with an SS of 2 or more was $8.6 \%$ with one eye drop, $18.7 \%$ with two drops, $35.9 \%$ with three eye drops and $57.1 \%$ with four or five eye drops. As the number of eye drops increased, SPK became more frequent and severe. The incidence and SS value were not different between male and female patients by Chi-square and Mann-Whitney $U$-tests.

The incidence, average SS, number of eye drops, and total dose frequency per day by age group are shown in Table 3. When the patients were separated into younger ( $\leq 70$ years) and older ( $\geq 71$ years) groups, incidence (Chisquare test, $P=0.0031$ ) and severity (SS, Mann-Whitney $U$-test, $P<0.0001)$ were significantly greater in the older age group. Similarly, there were significant differences in the number of eye drops (Mann-Whitney $U$-test, $P<0.0001$ ) and the total frequency per day (Mann-Whitney $U$-test, $P<0.0001)$. Next, we evaluated differences between the younger and older age groups based on the number of eye drops (Table 4). The incidence and severity were quite similar between the two age groups in eyes using only one eye drop. However, SPK tended to occur more frequently and severely in eyes with two eye drops, although this was not statistically significant. Finally, the incidence and severity were significantly greater in the older age group in eyes with three or more eye drops compared with the younger age group.
Table 2 The number of eyes from the AD classification

\begin{tabular}{llll}
\hline & Al & A2 & A3 \\
\hline DI & $254(33.9 \%)$ & $39(5.2 \%)$ & $20(2.7 \%)$ \\
D2 & $32(4.3 \%)$ & $14(1.9 \%)$ & $12(1.7 \%)$ \\
D3 & $3(0.4 \%)$ & $5(0.7 \%)$ & $2(0.3 \%)$ \\
\hline
\end{tabular}

Table 5 summarizes the number of eyes, average age, incidence and severity of SPK, number of eye drops, and total dose frequency per day for each type of glaucoma.

\section{Discussion}

In this study, almost half of the eyes using antiglaucoma eye drops previously had SPK with varying severities (Table 1). Two hundred fifty-four eyes (33.9\% of total and $66.5 \%$ of SPK-positive eyes) had only faint to mild SPK with an SS of 1 (A1D1). Severe SPK was detected in 18 eyes ( $2.4 \%$ of total) classified as SS 6 and in two eyes ( $0.3 \%$ of total) with SS 9 (Table 2). While the majority of cases of drug-induced keratoepitheliopathy had only mild SPK, there were a few severe cases associated with glaucomatous medication. ${ }^{23}$

Miyata et a ${ }^{31}$ evaluated the severity of SPK on a scale from 0 to 6 with values based on A + D. They reported that the fluorescein concentration in the cornea increased on a scale of 0 to 6 in a manner similar to a quadratic function. Therefore, we thought that a scale for evaluating the severity of SPK based on values of $A \times D$ may be more suitable than one using values of $\mathrm{A}+\mathrm{D}$, particularly for more severe cases. The incidence or severity of drug-induced keratoepitheliopathy was closely related to the number of eye drops or total dosing frequency per day as shown in Figures 1 and 2. The more eye drops that were used, the more frequent and more severe the SPK. In particular, all eyes that received four or more eye drops had combined SPK. Similar relationships can be seen between the incidence, severity, and total dose frequency per day. Both ophthalmologists and glaucomatous patients may have to tolerate faint to mild side effects in order to continue these medications because of the characteristics of glaucoma treatment. Mild SPK without any related subjective symptoms, such as foreign body sensation, irritation, or blurred vision may be permissible. Mild SPK means that within an SS of 1, the following percentage of eyes would

Table I The incidence of drug-induced SPK

\begin{tabular}{lllll}
\hline SPK & Number of eyes & Number of eye drops & $P^{\prime}$ & Total dose frequency per day \\
\hline$(-)$ & $367(49.0 \%)$ & $1.446 \pm 0.617(\mathrm{I}-3)$ & $<0.000 \mathrm{I}$ & $2.274 \pm \mathrm{I} .624(\mathrm{I}-\mathrm{I} 0)$ \\
$(+)$ & $382(5 \mathrm{I} .0 \%)$ & $\mathrm{I} .945 \pm 0.896(\mathrm{I}-5)$ & $3.622 \pm 2.442(\mathrm{I}-\mathrm{I})$ & $<0.000 \mathrm{I})$ \\
\hline
\end{tabular}

Note: 'By the Mann-Whitney U-test.

Abbreviation: SPK, superficial punctate keratitis. 


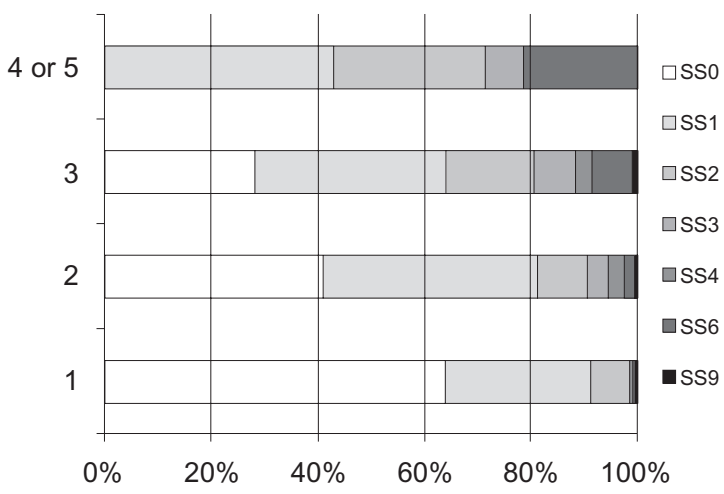

Figure I The number of eyedrops and SPK severity score (SS). Abbreviation: SPK, superficial punctate keratitis.

be worse than the tolerated level: $8.6 \%$ of eyes with one eye drop, $18.7 \%$ with two, $35.9 \%$ with three, and $57.1 \%$ with four or five eye drops.

Drug-induced keratoepitheliopathy is thought to be closely related to age because tear secretion decreases ${ }^{34}$ and the epithelial proliferative activity changes with age.${ }^{13}$ In this study, eyes in the older age group had more frequent and severe SPK (Table 4). However, the number of eye drops and total dose frequency per day were also related to severity of SPK. Thus, we evaluated patients based on the number of eye drops and their age (over or under age 70 years). Although the incidence and severity were similar in the eyes using only one eye drop, eyes that received two eye drops had more frequent and severe SPK in the older age group, although these increases were not statistically significant. Finally, the older age group using three or more eye drops showed a statistically significant difference (Table 5). As with the number of eye drops, advancing age may increase the likelihood of drug-induced keratoepitheliopathy.

In addition, a considerable difference was detected based on the type of glaucoma. We compared them with open angle glaucoma (OAG, including POAG and NTG), which is a basic type of glaucoma. The eyes with ocular hypertension tended to use fewer eye drops and to have less combined SPK. In pseudoexfoliation glaucoma, the incidence and severity as well as the number of eye drops were increased compared with those in OAG. Eyes with primary angle-closure glaucoma had more frequent and severe SPK, although the number of eye drops and total dose frequency per day were similar with OAG. However, the reasons for these differences are unknown. Eyes with uveitis had more SPK when more than one eye drop was used, and 3- to 4-fold higher total dose frequencies, compared with OAG, probably because one or more steroid or non-steroid eye drops were used to treat uveitis. While eyes with neovascular glaucoma used fewer eye drops than those with uveitis, SPK was remarkably more frequent and severe. Almost all cases of NVG had combined proliferative diabetic retinopathy as well as diabetic keratopathy. Therefore, the corneal epithelium with NVG appears to be easier to injure but harder to improve. Specific differences in drug-induced keratoepitheliopathy may depend on specific treatments for each type of glaucoma.

The general incidence of SPK was reported to be $1 \%$ to $2 \%$, based on clinical trials for antiglaucomatous eye drops. These findings raise the question of why SPK has been commonly reported in clinical practice. Although glaucomatous patients increase with age, patients in the older age group are usually excluded from clinical trials. Only one eye drop is usually given in clinical trials, or two at most for post-marketing surveillance purposes. Furthermore, clinical trials set a washout period (usually one month) before starting eye drop therapy. If the subjects had SPK when using antiglaucomatous eye drops, SPK should have disappeared during one month without medication. Without eye drops, the condition of the ocular surface, including the corneal epithelium and tear film, must have improved and become resistant to eye drops for several weeks to months. In clinical practice, many glaucomatous patients have to continue using one or more eye drops for long time periods, basically for a lifetime in the case of POAG or NTG patients. These patients often belong to the older age group. Thus, the background of drug-induced keratoepitheliopathy must be much more severe and difficult to improve in clinical practice than in clinical trials. In this study, we also recorded which drugs were used for specific eyes. Instead of the number of eye drops, the types

Table 3 Age groups and the incidence of SPK

\begin{tabular}{llllll}
\hline Age & Eyes & SPK $(+)$ & Severity $($ SS) & Number of eye drops & Total dose frequency per day \\
\hline-50 & 67 & $41(61.2 \%)$ & $0.784 \pm 0.893$ & $1.769 \pm 0.632$ & $3.108 \pm 1.913$ \\
$51-60$ & 109 & $44(40.2 \%)$ & $0.691 \pm 1.260$ & $1.710 \pm 0.858$ & $2.784 \pm 2.172$ \\
$61-70$ & 193 & $83(43.0 \%)$ & $0.686 \pm 1.034$ & $1.567 \pm 0.721$ & $2.432 \pm 1.874$ \\
$71-80$ & 251 & $140(55.8 \%)$ & $1.107 \pm 1.562$ & $1.756 \pm 0.830$ & $3.186 \pm 2.487$ \\
$81-$ & 129 & $72(55.8 \%)$ & $0.858 \pm 1.081$ & $1.819 \pm 0.826$ & $3.614 \pm 2.591$ \\
\hline
\end{tabular}

Abbreviations: SPK, superficial punctate keratitis; SS, severity score. 
Table 4 SPK by the number of eye drops and age groups

\begin{tabular}{llllll}
\hline Number of eye drops & Age group & eyes & SPK (+) & $\boldsymbol{P}^{\prime}$ & Severity (SS) $^{P^{2}}$ \\
\hline $\mathrm{I}$ & $\leqq 70$-year-old & 187 & $70(37.4 \%)$ & $0.738 \mathrm{I}$ & $0.459 \pm 0.684$ \\
& $\geqq 7$-year-old & 161 & $57(35.4 \%)$ & & $0.510 \pm 0.860$ \\
2 & $\leqq 70$-year-old & 129 & $68(52.7 \%)$ & 0.0904 & $0.875 \pm 1.316$ \\
& $\geqq 7$-year-old & 155 & $98(63.2 \%)$ & & $1.077 \pm 1.297$ \\
3 & $\leqq 70$-year-old & 45 & $25(56.6 \%)$ & 0.0018 & $1.159 \pm 1.509$ \\
& $\geqq 7$-year-old & 58 & $49(84.5 \%)$ & & $1.948 \pm 1.959$ \\
\hline
\end{tabular}

Notes: 'By the chi-square test. ${ }^{2}$ By Mann-Whitney U-test. Abbreviation: SPK, superficial punctate keratitis.

of eye drops or the combinations of eye drops may affect the incidence and severity of keratoepitheliopathy. We intend to examine these possibilities in the near future.

Faint to mild side effects such as keratoepitheliopathy need to be tolerable with glaucomatous treatment. However, we have to avoid or minimize these side effects as much as possible, even if patients are not aware of them. For example, among eye drops that have similar efficacy in reducing IOP, we should select glaucomatous eye drops that are the safest for the ocular surface. For older patients who have mild visual field defects, we recommend that their first glaucomatous eye drop is chosen from ones that are safe and/or have mild effects on the ocular surface. When moderate to severe drug-induced keratoepitheliopathy is discovered, we would first suggest changing the eye drops. However, these conditions are often hard to improve because they have different backgrounds, such as dry eyes and Meibomian gland dysfunction. We have to consider seriously suspending aggressive treatments with eye drops. Using only preservative-free tear eye drops might normalize the conditions of the ocular surface, tear film, and corneal epithelium after a period of time. After that, we can try individual eye drops that are safer for the cornea. Finally, we have to perform glaucoma surgery instead of medicating in severe cases of drug-induced keratoepitheliopathy.

As a general concept, drug-induced keratoepitheliopathy results from a combination of the active drug and the vehicle, including preservatives and additives. ${ }^{10-30}$ In particular, $\mathrm{BAC}$ is a preservative that is toxic to the cornea. ${ }^{13-16}$ Recently, some eye drops without preservatives or BAC have become available for glaucomatous treatment., ${ }^{41-12}$ While preservative-free glaucomatous eye drops have been introduced using small unit-dose bottles, ${ }^{4}$ a membrane filter can be set on the top of the bottle to make some glaucomatous eye drops preservative-free. ${ }^{11,12}$ In addition, there are other glaucomatous eye drops that use non-BAC preservatives. ${ }^{4,5,35}$ BAC can actually injure the barrier function of the corneal epithelium. ${ }^{13}$ While this might relate to the corneal epithelial damage caused by BAC, it also might make the eye drops penetrate further into the eye through the cornea. Some previous reports have confirmed the benefits of BAC-free antiglaucoma eye drops. ${ }^{4,5,10-12,24,25}$ Ishibashi et a ${ }^{24}$ reported that preservative-free timolol did not reduce non-invasive breakup time. On the other hand, anti-glaucoma eye drops without BAC may have weaker effects on IOP reduction than

Table 5 Diagnosis of glaucoma and the incidence of SPK

\begin{tabular}{lllllll}
\hline Dx & Eyes & Age & SPK $(+)$ & Severity (SS) & Number of eye drops & $\begin{array}{l}\text { Total dose frequency } \\
\text { per day }\end{array}$ \\
\hline OAG & 565 & $69.0 \pm 12.1$ & $274(48.5 \%)$ & $0.759 \pm 1.107$ & $1.681 \pm 0.779$ & $2.877 \pm 2.283$ \\
XFG & 52 & $76.1 \pm 6.9$ & $30(57.7 \%)$ & $1.000 \pm 1.278$ & $1.860 \pm 0.728$ & $2.220 \pm 1.844$ \\
PAC/G & 40 & $73.8 \pm 8.1$ & $27(67.5 \%)^{*}$ & $1.410 \pm 1.585^{\#}$ & $1.641 \pm 0.778$ & $3.000 \pm 2.284$ \\
Uveitis & 22 & $63.9 \pm 14.5$ & $16(72.7 \%)^{*}$ & $1.772 \pm 1.998^{\#}$ & $2.500 \pm 1.225^{\#}$ & $6.180 \pm 4.283^{\#}$ \\
OH & 20 & $65.4 \pm 15.9$ & $6(31.5 \%)$ & $0.400 \pm 0.754$ & $1.200 \pm 0.410^{\#}$ & $2.250 \pm 1.112^{*}$ \\
NVG & 15 & $68.5 \pm 11.0$ & $14(93.3 \%)^{\#}$ & $2.500 \pm 2.653^{\#}$ & $2.285 \pm 0.825^{\#}$ & $4.929 \pm 2.056^{\#}$ \\
\hline
\end{tabular}

Notes: $* P<0.05, \# P<0.01$ against for OAG.

Abbreviations: OAG, Primary open-angle glaucoma with normal tension glaucoma; XFG, Pseudoexfoliation glaucoma; PAC/G, Primary angle-closure or primary angle-closure glaucoma; Uveitis, Glaucoma with uveitis or iridocyclitis; OH, Ocular hypertension; NVG, Neovascular glaucoma; SPK, superficial punctate keratitis. 


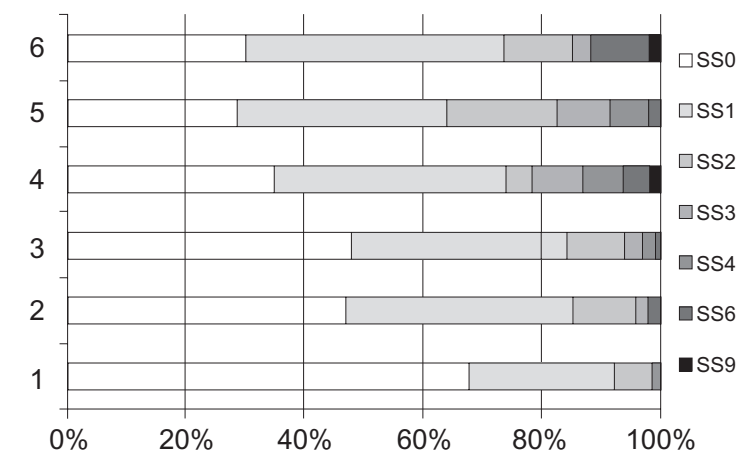

Figure 2 The total dose frequency per day and the SPK severity score (SS). Abbreviation: SPK, superficial punctate keratitis.

those with BAC. For travoprost, the ability to reduce IOP was quite similar with and without BAC., ${ }^{4,5}$

A limitation of this study was that we did not confirm the incidence of SPK in glaucomatous patients without eye drops. This is supposed to be about $10 \%$, but these patients are not typical glaucomatous cases. Because they often had histories of glaucoma surgery or very mild visual field defects, it was not necessary to apply eye drops to treat glaucoma. Another limitation was that we examined each eye only once within the study period. With repeated examinations, SPK often appears and disappears by chance, even in the same eye. Drug-induced keratoepitheliopathy may also be influenced by seasonal or regional differences. Dry eye, Meibomian gland dysfunction, or a history of ocular surgeries might also relate to these conditions as background complications. Further studies are warranted that include these conditions.

Drug-induced keratoepitheliopathy may be more frequently observed after treatment with antiglaucomatous medication. The number of eye drops, the total dose frequency per day, age of the patient, and type of glaucoma might relate to this condition. We have to consider not only their effects on IOP, but also the incidence and severity of drug-induced keratoepitheliopathy as the most frequent side effect of glaucoma medication. In particular, careful observation is needed for the eyes that are treated with multiple eye drops in older age groups.

\section{Disclosures}

The authors report no conflict of interest in this work.

\section{References}

1. Alm A, Stjernschantz J. Effect on intraocular pressure and side effect of $0.005 \%$ latanoprost applied once daily, evening or morning. Ophthalmology. 1995;102(12):1743-1752.

2. Watson P, Stjernschantz J. A six-month, randomized, double-masked study comparing latanoprost with timolol in open-angle glaucoma and ocular hypertension. Ophthalmology. 1996;103(1):126-137.
3. Camras CB. The United States latanoprost study group. Comparison of latanoprost and timolol in patients with ocular hypertension and glaucoma. Ophthalmology. 1996;103(1):138-147.

4. Lewis RA, Katz GJ, Weiss MJ, et al. Travoprost $0.004 \%$ with and without benzalkonium chloride: A comparison of safety and efficacy. J Glaucoma. 2007;16(1):98-103.

5. Gross RL, Peace JH, Smith SE, et al. Duration of IOP reduction with travoprost BAC-free solution. J Glaucoma. 2008:17(3);217-222.

6. Donohue EK, Wilensky JT. Trusopt. A topical carbonic anhydrase inhibitor. J Glaucoma. 1996;5(1):68-74.

7. Araie M, Kitazawa Y, Azuma I, et al. The efficacy and safety of dose escalation of dorzolamide used in combination with other topical antiglaucoma agents. J Ocul Pharmacol Ther. 2003;19(6):517-525.

8. Silver LH. Clinical efficacy and safety of brinzolamide (Azopt), a new topical carbonic anhydrase inhibitor for primary open-angle glaucoma and ocular hypertension. The Brinzolamide Primary Therapy Study. Ophthalmology. 1998;126(3):400-408.

9. Konstas AG, Mantziris DA, Maltezos A, et al. Comparison of 24 hour control with Timoptic $0.5 \%$ and Timoptic-XE $0.5 \%$ in exfoliation and primary open-angle glaucoma. Acta Ophthalmol Scand. 1999;77(5):541-543.

10. Baudouin C, de Lunard C. Short term comparative study of topical $2 \%$ carteolol with or without benzalkonium chloride in healthy volunteers. Br J Ophthalmol. 1998;82(1):39-42.

11. Piesella PJ, Fillacier K, Elena PP, et al. Comparison of the effects on preserved and unpreserved formulations of timolol on the cornea surface of albino rabbits. Ophthalmic Res. 2000;32(1):3-8.

12. Pisella PJ, Pouliquen P, Baudouin C. Prevalence of ocular symptoms and signs with preserved and preserved-free glaucoma medication. Br J Ophthalmol. 2002;86(4):418-423.

13. Edelhauser HF, Ubels J. The cornea and the sclera. In: Kaufman PL, Alm A, editors. Adler's Physiology of the Eye. 10th ed. St. Louis, MO: Mosby; 2003:47-114.

14. Pfister RR, Burstein NL. The effects of ophthalmic drugs, vehicles, and preservatives on corneal epithelium: A scanning electron microscope study. Invest Ophthalmol Vis Sci. 1976;15(4):246-259.

15. Burstein NL. Corneal toxicity of topically applied drugs, vehicles and preservatives. Surv Ophthalmol. 1980;25(1):15-30.

16. De Saint Jean M, Brignole F, Bringuier AF, et al. Effects of benzalkonium chloride on grows and survival of Chang conjunctival cells. Invest Ophthalmol Vis Sci. 1999;40(3):619-630.

17. Fraunfelder FW. Corneal toxicity from topical ocular and systemic medications. Cornea. 2006;25(10):1133-1138.

18. Herreras JM, Pastor JC, Calonge M, Asensio VM. Ocular surface alteration after long-term treatment with an antiglaucomatous drug. Ophthalmology. 1992;99(7):1082-1088.

19. Broadway D, Grierson I, Hitchings R. Adverse effects of topical antiglaucomatous medications on the conjunctiva. $\mathrm{Br} J$ Ophthalmol. 1993;77(9):590-596.

20. van Buskirk EM. Corneal anesthesia after timolol malate therapy. Am J Ophthalmol. 1979;88(4):739-743.

21. Wilson RP, Spaeth GL, Poryzees E. The place of timolol in the practice of ophthalmology. Ophthalmology. 1980;87(5):451-454.

22. Weissman SS, Asbell PA. Effects of topical timolol (0.5\%) and betaxolol (0.5\%) on corneal sensitivity. Br J Ophthalmol. 1990;74(7):409-412.

23. Inoue $\mathrm{K}$, Okugawa $\mathrm{K}$, Kato $\mathrm{S}$, et al. Ocular factors relevant to antiglaucomatous eyedrop-related keratoepitheliopathy. J Glaucoma. 2003;12(6):480-485.

24. Ishibashi T, Yokoi N, Kinoshita S. Comparison of the short-term effects on the human corneal surface of topical timolol maleate with and without benzalkonium chloride. J Glaucoma. 2003;12(6):486-490.

25. De Saint Jean M, Debbasch C, Brignole F, et al. Toxicity of preserved and unpreserved antiglaucoma topical drugs in an in vitro model of conjunctival cells. Curr Eye Res. 2000;20(1):85-94.

26. Guenoun JM, Baudouin C, Rat P, et al. In vitro study of inflammatory potential and toxicity profile of latanoprost, travoprost, and bimatoprost in conjunctiva-derived epithelial cells. Invest Ophthalmol Vis Sci. 2005;46(7):2444-2450. 
27. Ayaki M, Noda Y, Yaguchi S, et al. Cytotoxicity of antiglaucoma ophthalmic solutions for human corneal endothelial cells. J Jap Ophthalmol Soc. 2009;113(5):576-582.

28. Leung EW, Mediros FA, Weinreb RN. Prevalence of ocular surface disease in glaucoma patients. J Glaucoma. 2008;17(5):350-355.

29. Lass JH, Khosrof SA, Laurence JK. A double masked, randomized, 1-year study comparing the corneal effect of dorzolamide, timolol, and betaxolol. Arch Ophthalmol. 1999;116(8):1003-1010.

30. Reidy JJ, Zarzour J, Thompson HW, Beuerman RW. Effect of topical beta blocker on corneal epithelial wound healing in the rabbit. $\mathrm{Br} J$ Ophthalmol. 1994;78(5):377-380.

31. Miyata K, Amano S, Sawa M, Nishida T. A novel grading methods for superficial punctate keratopathy magnitude and its correlation with corneal epithelial permeability. Arch Ophthalmol. 2003;121(11): 1537-1539.
32. European Glaucoma Society. Terminology and Guidelines for Glaucoma. 3rd ed. 2008. Available from: http://www.eugs.org/eng/ EGS_guidelines.asp. Accessed Feb 28, 2010.

33. Japan Glaucoma Society. Guidelines for Glaucoma. Tokyo, Japan: Japan Glaucoma Society; 2002.

34. Lucarelli MJ, Dart DA, Cook BE, Lemke BN. The lacrimal system. In: Kaufman PL, Alm A, editors. Adler's Physiology of the Eye. 10th ed. St. Louis, MO: Mosby; 2002:30-43.

35. Whitson JT, Ochsner KI, Moster MR, et al. The safety and intraocular pressure-lowering efficacy of brimonidine tartrate $0.15 \%$ preserved with polyquaternium-1. Ophthalmology. 2006;113(8):1333-1339.
Clinical Ophthalmology

\section{Publish your work in this journal}

Clinical Ophthalmology is an international, peer-reviewed journal covering all subspecialties within ophthalmology. Key topics include: Optometry; Visual science; Pharmacology and drug therapy in eye diseases; Basic Sciences; Primary and Secondary eye care; Patien Safety and Quality of Care Improvements. This journal is indexed on

Submit your manuscript here: http://www.dovepress.com/clinical-ophthalmology-journal

\section{Dovepress}

PubMed Central and CAS, and is the official journal of The Society of Clinical Ophthalmology (SCO). The manuscript management system is completely online and includes a very quick and fair peer-review system, which is all easy to use. Visit http://www.dovepress.com/ testimonials.php to read real quotes from published authors. 